\title{
Law as Transformative Conflict Work - A Transrational Approach
}

\author{
Florencia Benítez-Schaefer
}

Submitted: November 2013

Accepted: June 2014

Published: November 2014

\section{Abstract}

This paper addresses the question of how law and legal work can be envisaged from a perspective of transrational peaces and within an approach of elicitive conflict transformation. The narrative of law is connected here to the perspectives of energetic, moral, modern and postmodern peaces as elaborated by Wolfgang Dietrich, and addresses particularly the shortcomings of a fragmented approach to law when it comes to respond to complex social conflicts. The author presents how a transrational approach can foster the necessary awareness and transformation of crucial aspects of human relations within the work in the field of law. To illustrate this, the text provides some examples from different fields of legal praxis, which show that multiple perspectives on law are currently interacting in order to address social conflict. Most importantly, these examples demonstrate that a transrational and transformational approach to law is not only possible, but rather that it is already taking place.

\section{Keywords}

transrational law, many peaces, law, elicitive conflict transformation

\section{INTRODUCTION: SISTER JUSTICE, SISTER PEACE ...}

The sky is clear, the field is vast. Dancing in rhythm with each other, Dike, Eirene and Eunomia, the golden Horae, mark the passing of time. Through the ways they move in their rhythmic flow, they allow time to be reborn over and over. They stamp the ground with all their weight, and, when they gently lift their feet, out of each of their footprints life arises from Earth again and again, season by season. The cycles of birth and death become possible and meaningful through their playful encounter. Constant recreation of life depends on the interplay of their power, grace and virtue.

The three beings in movement, mystic holders of law, peace and good government, give form to themis - the divine law of ebb and flow, of times of wealth and times of scarcity, of giving and taking. Through their dance, they connect heavenly and earthly realms, the ethereal divine and the concrete shapes that life takes over and over - always different, always the same. They are ultimately the result of the eternal encounter between Heaven and Earth, Uranus and Gaea, progenitors of the matrix that gave birth to the three sisters: Themis.

Law, thus, is nothing more than a dance with the divine.

For sure, the image of a dancing law, justice, government or order might appear quite strange today when we are confronted daily with the formal structures of codes, contracts and courts, and the bureaucracy connecting them. Rather than a dance it might feel like moving within a spiky labyrinth of wires. Nevertheless, what every judge and legislator still advocates today in the name of law and justice is the act of balance this type of work implies, a balance that goes beyond the structural capacity of the scales of Justice. It includes a myriad of elements beyond positive law that need to find a certain equilibrium with each 
other, a fragile - but oh-so-needed! - balance of freedoms and securities, social needs and individual needs, plaintiff A and plaintiff $B$, rights and obligations, change and stability, equality and particularity, general abstraction and individual concreteness, understanding and determination. What is law but a subtle exercise of continuous balance, a dynamic balance or, in other words, an exercise in making and re-making peace?

Beyond a mythological, cosmic and energetic vision of peace and justice like the one presented above, their intimate connection remains present at the core of the most naturalistic moral and the most positivistic modern legal argumentation. Thus, in cases of social claims for peace and justice, the response is often a change in the wording or in the implementation of law. Similarly, the shift from physical clashes to a confrontation mediated by legal institutions is often seen as a positive progress of the conflict. Justice, Peace and Government are still sisters shaping the passage of time in human existence.

Hence, a modern peace in terms of the Pax Romana requires a legal contract in line with positivistic modern law that claims validity and legitimacy by its very existence, by the very stamp it takes: 'LAW'. As different understandings of peace might enter in conflict, so also different notions of law might be opposed to each other or to some forms of peace. Moral justice and the law embodying it, with its promises of a better and more righteous world, are easily at odds with a mechanistic understanding of peace. Likewise, it is against a universalized and centralized vision of law that the postmodern voices of many peripheral 'Others' have been raised claiming the subjectivity and plurality of law.

And now that we are here, at the edge of time, we realize that not only Eirene, Dike and Eunomia are dancing softly on Earth, but also that Kali is jumping around while Gambian jokers ${ }^{1}$ are laughing in grief and some devotees are making an offering to Pachamama with coca and cigars. Justitia walks through the field of dancers, and, blind as she is, she stumbles into a dancer here and steps on the feet of another there. Brandishing her sword, she puts the hands of friends in danger and cuts the tongues of strangers.

Eventually, she might say sorry, but that does not stop her in her detour.

Now, after Chaos has burst onto the scene, the question is: can we still dance together?

In the last decades, peace and conflict studies have developed an approach that aims to transcend this conundrum by integrating the different aspects involved. This is the shift from conflict resolution to conflict transformation. A transrational model of peaces in interaction suggests that there is a chance to engage with each other beyond the rational dichotomies of 'You' and 'I', of 'Us' and
'Them'; it is possible to re-shape our relations through conflict, in conflict, beyond conflict. Acknowledging interdependency and autonomy, combining complementarity and choice, peace is just in the palm of our hands and in the depth of our bellies.

But how does this work for 'your law and your justice' and my 'law and my justice'? Can law, as paramount form of conflict resolution, add something to conflict transformation? If yes, how? And if not - how do we deal with that? Funnily enough, at times it seems that the epistemes and visions of conflict transformation and law, if they enter in contact with each other at all, get entangled in conflict. How does upright law, as a highly institutionalized and hierarchical modern project (with moral and postmodern overtones) match a transrational perspective that aims, precisely, to twist these approaches, incorporating energetic aspects? Is law's role in this transrational game merely restricted to acknowledging its limitations and stepping back from the center stage? Or is it desirable that the primacy of law and justice subsist within the dynamic integration that transrationality proposes? Has the time come for law to twist?

\section{TWISTING LAWS}

As I have presented briefly above, law is connected with peace in manifold ways. Law, as much as peace, has many aspects which are emphasized more or less depending on the perspective taken regarding what it means to be a human being in relation with others, the environment and with a larger whole. Talking about law, an approach of integrative transrational peaces and elicitive conflict transformation requires that we first ask what needs to be integrated and what makes the shift from conflict resolution to conflict transformation necessary and meaningful in this field. To this end I address the question of how the different perspectives on law can be organized in relation to the families of peaces proposed by Dietrich (2008). Following this perspective of energetic, moral, modern and postmodern peaces, the narrative of law can be connected to notions of harmony, justice, security and/or truth. The consequences of taking one of these different approaches determine the role of law within conflict and peace work.

Remarkably, the dominant narrative on law today is a combination of moral and modern understandings, which, in terms of legal philosophy are represented by iusnaturalistic and iuspositivistic currents. One of the principles of modern law is that the subjects of law are autonomous and therefore take individual responsibility for their actions from buying an ice-cream to commanding genocide. How- 
ever, from a systemic perspective, Dietrich (2008, p. 396) emphasizes the limitations of both realistic ${ }^{2}$ and idealistic approaches to human interaction as a mere matter of individual reactions.

It is a simplistic and vectoral idea based on realistic understandings, the one at the base of the assumptions that law needs to control individual impulses in order to create order and secure freedom, that it needs to punish in order to discourage specific behaviors, that society needs one ultimate authority to subdue chaos. This approach to law is defined by fear and therefore seeks to be led by the primacy of security. Importantly, fear does not characterize only criminal law, but is at the core of other parts of public as well as civil law. It is the same fear that lies behind strict contractual formalities and their subsidiary norms, and it is the same fear that guides the regulations determining that a citizen will be denied certain rights if specific standardized conditions are not fulfilled. Particularly in the field of social law, it becomes clear that fear reproduces fear. And so it is no surprise that law becomes a paradigmatic example of Dietrich's statement regarding realistic approaches, that "fear as a characteristic of relations blockages the free flow of life energy, restricting the concretization of peace ethics" (Ibid, p. 397). In this sense, positivistic modern legal theory at the ground of positivistic modern legal practice is one of those "theories or even ideologies led by fear that serve neither the research nor the practice of peace in a holistic manner" (Ibid).

At the same time, it is in line with an idealistic understanding of law that it is defined, following a Kantian tradition, by a division between what is and what should be, sein and sollen. The hope for a righteous world, where everything is as it should be, takes shape in the hope and claim for justice in moral terms. How should a society be? How should a citizen behave? Towards which ideal should we orient our actions? These are the leading questions of legislative, but also judicial and administrative legal engagement. This is one more expression of the violence ingrained in abstract and generalized expectations that claim to be universally valid.

But this claim for an absolute truth is difficult to maintain once plural voices become loud, exposing the concrete beings-in-relation as marked by their internal individual and communal frames of reference and action. Postmodern approaches to peace and law have addressed these aspects explicitly, engaging with what Dietrich calls an approach to peace out of truth, while truth is always an expression of shared and thus contingent meaning. Consequently, questions of plurality barge in, and we end up with peaces out of truths, and laws out of cultures. Lastly, in this struggle for survival of the own truth, peace and law become mat- ters of power, particularly the discursive power of asserting legitimacy to the own truth.

In the theory and praxis of law we therefore find legal-political struggles connected to Critical Legal Studies, Legal Pluralism (e.g. in the Bolivian constitution) and the constant search for alternative approaches to law as a reaction to authoritarian regimes in Europe and America (Benítez-Schaefer, unpublished). However, while postmodern approaches brought new models, they did not necessarily bring about more peace, but rather pluralized the clashes they aimed to address or fell back into moralmodern structures (Ibid).

Problematically, solving conflicts as moral-modern law promised, namely via applying justice through structured institutions, requires a standard, a measure stick, a generally valid norm. However, this is not compatible with a pluralistic and culturalistic understanding of law. The most that this type of legal institution embedded in this postmodern condition can offer, beyond violent imposition, is the transposition of conflicts from one field to the next. A merely pluralistic approach to law, however, does not support shared coexistence either, but breaks down into clashing particularities.

In other words, merely applying an approach of conflict resolution according to moral-modern or postmodern perspectives within law to social conflicts does not access their full potential in a holistic and constructive manner. Rather, the complex of social tension that is lived out within legal confrontation is frozen or ignites into violent clashes. The possibility of transformation is derived, in turn, to fields like social work, which nevertheless are restricted in their action by the legal framework. This is the struggle that we, as agents of law, peace and conflict are currently facing. This is the struggle that a transrational and transformative approach aims to address.

\section{LEGAL RELATIONS AS HUMAN RELATIONS}

A transrational and transformational approach proposes that the main difficulty of these models lies in the lack of awareness of crucial aspects of human relations. As I have argued, building on Dietrich's elaborations, fear and hope are both combined in a modern-moral understanding of law and pluralized in postmodern forms of legality, leaving little space for crucial questions regarding the actual relationships amongst the participants involved in a conflict. Particularly, these relations include, in a determinant 
manner, also those allegedly passive, neutral or in principle exchangeable actors around the conflict. In the realm of law these peripheral actors particularly include judges, lawyers, administrative staff and the teams around them.

In terms of legal 'fights', it is interesting to realize that only due to the regularly lacking awareness of this relational aspect is it possible to speak of a 'fight', understanding fight as based on the dynamic in which the "adversaries are identified with their thoughts and with a posture that reacts to the position of the other party and fends it off" (Dietrich, 2008, p. 366). This is the identification that hinders the experience of a transrational peace in terms of Dietrich's interpretation of humanistic (transpersonal) psychology. In itself, identification requires a projection of the person into the past and into the future. Problematically, being too busy with the created images of past and future, and the fears and hopes attached to them, does not allow for acknowledging present perceptions, present feelings and present thoughts. Consequently, fully present engagement with peace and conflict is hindered. Current needs are neglected and one's own role in the web of relations is overlooked.

Furthermore, understanding peace and conflict as matters of human relations implies that, through the change of the position of each actor within the system of relationships, not only their own perspective of the whole complex changes but also the complex itself. In other words, the level of awareness and engagement of the individual actors determine the quality of the conflict and, subsequently, how it transforms. Understanding and engaging with social relations fully requires addressing all of their components.

According to the humanistic psychologist Ken Wilber, human relations include internal as much as external aspects at individual and communal levels (Wilber, 2000, pp. 127-157, 192-199). While the disciplinary fields of engagement with social relations, namely social sciences including law, have focused on the external aspects of human communication and behavior, the other fields that are necessarily present and determinant for social relations are generally left aside. Thus, in Dietrich's elaboration of Wilber, an understanding of peace out of justice (externalcommunal aspect) or peace out of security (external-individual aspect) corresponds very much to the promises of moral-modern law in its iusnaturalistic and iuspositivistic components. Postmodern approaches to peace and law have emphasized, in turn, the internal-communal worlds of shared meaning, culture.

What currently remains poorly addressed in the field of legal reflection, however, is the internal-individual aspect of human relations, communications and behavior: what Dietrich calls the understanding of peace out of harmony - a peace that is characterized, firstly, by its connection to the unique moment and space where its experience takes place, and secondly, by a constant recreation of dy- namic and holistic balance. Going beyond all dichotomies, it also transcends the dichotomy of individual vs. world, connecting the most intimate experience of peace with a cosmic Oneness. This is a world beyond social roles that, nevertheless, informs them dramatically. Its shape might be influenced by culture, morals and modern institutions of justice and it might find expression through these fields, but it builds an own realm of experience irreducible to all the others (Dietrich, 2008, p. 388).

In the face of this epistemic hole, we have at least two basic options: 1) "No, law does not care about your individual experience, nor about your cosmic connections!"; or 2) we say goodbye to law in its moral, modern and postmodern shapes, put all our hopes into harmony and leave it up to individual internal experiences of peace: "Who cares about outside law? Eirene, Dike and Eunomia dance in divine harmony anyways!" Eirene, Dike and Eunomia dance in divine harmony anyway! Taking only these two possibilities into account would result in quite a modern approach to dealing with the tension created by this challenge. Remarkably, the first approach could be understood as a form of self-assertion dominated by fear, and the second approach as a form of self-abandonment dominated by hope.

In turn, a transrational approach proposes a dynamic integration of the energetic aspect with the other three. Going back to the beginning of this paper, a harmonic approach to law can be depicted, in Eurocentric narratives, by the figures of the Horae Dike and her mother Themis. Re-membering them into moral, modern and postmodern understandings of law reestablishes the relations between law and cosmic harmony. In other words, it permits us to understand law as a matter of participating in the building of a bio-psycho-social dynamic balance and as an issue intimately connected to the constant recreation of life. In other words, it invites us to envisage the work with and through law as elicitive conflict transformation.

So far, I have underlined the connection of the law with what Dietrich addresses as the "Theme Pyramid" in Elicitive Conflict Mapping (Dietrich, unpublished) that Echavarría presents in this issue. Going further into the elaboration of law within a transrational perspective, and entering into its operationalization in terms of elicitive conflict transformation, it is worth noticing that legal matters are usually addressed at the level of the episode of the conflict between personae without using its whole potential to engage with all the layers involved. While law does deal with issues of 'family', 'community', 'society' and 'policy', the counterparts of these layers, namely 'sexual', 'socioemotional,' 'mental' and 'spiritual' aspects generally remain excluded from the visualization of the conflict, although they are constantly touched upon under the mask of legal arguments. There lies a hidden potential of law as a form of conflict and peace work.

While law as a human endeavor is naturally connected to the different layers of the persona, its modern narra- 
tive, with rational arguments focused on the mind, links it particularly to the mental-societal layers. Importantly, the potential of consciousness hosted here, connected to the anahata chakra which stands for mind and heart, puts the legal professional in a privileged position to transform "transrational qualities like love, compassion, and devotion, by bringing them into the episode [...] and by rendering them conscious experiences" (Dietrich, 2013, p. 216). But in order to do that, mental clarity in terms of the intra- and interpersonal layers of their own persona is indispensable. Understanding legal workers as elicitive conflict workers allows us to envisage the importance of including the work on the self in their education, for example by following some of the guidelines offered by Dietrich in this issue.

Equally, this new perspective unveils the immense potential of professionals of the law as catalysts of the conflict energy that can provide a safe space and facilitate transformative courses of action. The tool of Elicitive Conflict Mapping elaborated by Dietrich can offer some guidelines in this regard. For example, the focus of different fields of legal work can be related to the different layers surrounding the episode. Consequently, the work of judges can be understood as more connected with mental-societal layers, while lawyers can be understood as focusing more on the communal and therefore the socio-emotional layers of the personae in the conflict system. Along these lines, legislative and legal development work, related rather to policitary issues, could therefore be linked directly to spiritual concerns. At the other end of the chain of legal events, the executors of law, dealing with the intimacy of its concretization within families, can be seen as connected to sexual layers. This type of approach opens a whole new world of possibilities within the field of law that needs to be explored further.

In this sense, legal work can become elicitive peace work in the sense of Lederach, namely an engagement "characterized by intentional efforts to address the natural ebb and flow of human conflict through nonviolent approaches, which address issues and increase understanding, equality and respect in relationships" (Lederach, 2003, p. 21). Below, I will present some forms of engagement that open spaces within moral-modern and postmodern law, fostering integral awareness of the system of relations and its transformation.

\section{TRANSRATIONAL SHAPES OF LAW}

My father, a psychologist who lived almost half his life under Argentinean dictatorships, often expresses the connection between internal and external realms of human behavior by relating them to two disciplinary fields:
"Psychology and law are like two faces of a coin. One deals with what is inside a person, his motivations and asks: how is the world inside this person that he does this or that? The other deals with what is outside of him, his actions - and asks what does this person do and how does he affect the world outside? The one is about freedoms and limitations inside, the other about freedoms and limitations outside."

This idea is not new, but what is interesting about it is that it comes from one of the founders of forensic psychology in Argentina in 1989 (Sierra et al., 2010, p. 47) and a lifelong psychologist at the courts of Río Negro. If we transfer his perspective on law and psychology to the social field, my father was, in his social function, the coin he was speaking about. His statement remarks that there has always been a connection between law and psychology, and that it eventually became institutionalized through positions like his own.

In fact, an immense amount of legal decisions are directly informed (officially and unofficially) by reports on the psycho-social situation of the individuals involved in the legal action. Most often in criminal cases, but also in civil procedures, i.e. adoptions or even for entering the judiciary as a civil servant, the inner conflicts and peaces of thousands of individuals become part of crucial decisions in the legal field. Often these peace workers in the field of law also accompany the individuals after the legal process has ended, supporting the integration of legal acts into their individual bio-psycho-social worlds. Not only through the content of their actions, but most particularly through the quality of their engagement, addressing the deepest needs, the humanity and uniqueness of each person, civil servants like forensic psychologists mark encounters in the lives of their 'visitors' that fall outside the realm of explanations and arguments. In the middle of 'legal fights', they offer a space for finding or re-connecting with one's own harmony, with the presence of oneself and the awareness of oneself in relation to others.

Moreover, beyond incorporating the inner world of the ones on that side of the hierarchical legal structure - at the receiver's end of a decision, so to say - forensic psychologists and other collaborators on the backstage of modern law institutions play another crucial role. They support and engage with the motivations, desires, fears and internal struggles of the most visible actors of the judicial structure, influencing their explicit performance in the name of law. From receptionists to judges of the Supreme Court - all civil servants have access to direct or indirect advice and support from these professionals of 'the inner world' in matters related to their legal and personal performances. This takes place not only through individual consultations, but also through group meetings on topics of the 'inner world' that affect the 'outer world' of law, e.g. stress and burnout. Finally, these actors are often the ones 
in charge of linking the institutions of law with the broader collective. They address the "natural ebb and flow of human conflict in non-violent ways", as Lederach says, by facilitating experiences of empathy and communion, which might happen during seemingly banal presentations, debates, or other social interventions.

It is often through psychological reports that the internal-individual as well as internal-communal (cultural) aspects of human relations finds its way into judicial matters. As an example, we can present the case of an alleged sexual abuse in Argentinean Patagonia, in which cultural diversity was claimed in favor of the accused, on the grounds of a report by the forensic psychologist (Río Negro, 2002 , pp. $32 \mathrm{f}$.). In this case, the defendant was accused by his wife of regularly abusing her daughters. While sexual abuse is frequently a social problem that is met with clear rejection in political discourse, and which is the object of continuous demands for ever harder forms of punishment for the offenders, in this particular case, the prosecutor and the judge had to revise their own frames of reference and connect to experiential notions of harmony and cultural understandings of righteousness. The situation of confusion can be sensed during the trial, when, after eight months of separation, "at the moment of entering the tribunal, the complainant as well as each of the alleged victims greeted the accused individually [...] with a kiss on the mouth" (Ibid, p. 33, transl. FBS). The discussion in the court showed that none of the three women wanted the accused to be imprisoned and asked for his immediate liberation in order for him to return home (Ibid). How can the legal notion of 'abuse' be strictly upheld under these circumstances?

While the core of the arguments revolved around matters of cultural diversity, what is particularly important for our concern is the fact that internal aspects were able to enter the moral-modern legal structure via a psycho-social report. These internal aspects had communal components, particularly in terms of the interpretation, made by the officials, of certain behaviors related to the Araucano culture. But, most important, the members of the family included in their arguments their needs and actions on the basis of their innermost understandings of a harmonic life as individuals and as a family. The component of intentionality, linked to the internal-individual quadrant, becomes crucial for understanding (and judging) the actions at hand here. Most important, the civil servants oriented their response to the legally relevant facts according to the relations present amongst the accused, his wife and his step-daughters.

Importantly, the door for engaging with these aspects of social conflict and peace within law opens because the set structure of the application of law allows for it. In the case presented above, the questions that needed to be answered regarded the abilities of the individual to orient his actions and recognize the criminality of his deeds. In terms of the argumentative structure of legal cases, the matter appears under the rubrics of culpability, guiltiness and default. These are the fields where questions regarding the individual internal worlds of human beings involved in criminal cases are most commonly addressed. Unsurprisingly, these have been the areas where indigenousity has been alleged as an 'excusing' factor in the frame of criminal cases (Kuppe, 2010, p. 6).

Related to this situation, where the indigenous are marked by special forms of both criminalization and protection within state normativity, is the case of objections of conscience to military service in the context of the protracted Colombian conflict. While these objections have been partly accepted in line with the argument of 'cultural diversity', at the moment when non-indigenous citizens argue with their own cosmovision, new approaches are included in legal debate. This field has been researched from a peace studies perspective by Catalina Vallejo, who argues that several approaches to peace have their place within the modern framework of legal reasoning, interacting with each other and informing the outcome of legal conflicts (Vallejo, 2012). The lawyer and peace scholar shows, in a thorough analysis of various decisions of the Constitutional Court, how the plaintiffs and the judicial functionaries elaborated different arguments related to energetic, moral, modern, postmodern and transrational peaces.

Naturally, classical moral-modern arguments of the legal field were presented, for example, by the Colombian Ministry of Defense emphasizing the duties of the citizens according to the constitution. Energetic approaches were incorporated particularly in the arguments of indigenous communities. Postmodern perspectives were elaborated in the name of multiethnicity and multiculturality, also going beyond matters of indigenous groups, since the "lawsuit and the plurality of voices joining the talk, attempted to deconstruct some of the core (meta)narratives [...] upon which the norm of obligatory military service with no possible objection was sustained" (Ibid, pp. $123 \mathrm{f}$.). The most interesting aspect for us is the inclusion of transrational perspectives in the legal debate. In this line, Vallejo underlines the resort to "the notion of embodied peaces, nonviolent practices in the here and now and to the decision to deal with conflictive opposites in inclusive rather than exclusive ways" (Ibid, p. 131). Crucial at this point is the understanding of forms of making peace through the own presence and body, including energetic understandings within societies structured along modern principles (Ibid, p. 133).

In other words, Vallejo illustrates with this example that an integrative and transrational approach to law is not only possible, but, moreover, that it is already in action. Does this necessarily imply an approach of conflict transformation within or through law? Firstly, while we are still in the context of state law issuing an authoritative adjudication, these decisions imply a change in the relations between the state and the plaintiffs, certainly a key element within this 
particular socio-legal conflict. Secondly, and most importantly, this type of explicit argumentation opens the door for new types of encounter within and through the legal field. The fact of including the individual worlds of ethics, cosmovisions and experiences within the public debate and connects them with official moral, modern and postmodern discourses, and produces already crucial changes in the relations amongst the state judiciary, the objectors, their socio-cultural environment and the armed and nonarmed elements of the Colombian conflict in general. A more authentic and empathic engagement with persons in their particular realities becomes possible within the legal realm, permitting all participants to visualize the complex and dynamic system of interrelations in which they are embedded. Vallejo's work shows how different forms of argumentation can bring different laws and peaces to the foreground of legal engagement with conflicts.

Another interesting example in terms of the integration of these many aspects into a transformative perspective that goes beyond mere (legal) rationality is the renowned case of Cherán (Mexico) in 2012, which had major repercussions at the international level (OHCHRNU, 2011, p. 37). The core of the issue at hand was the demand of the villagers of Cherán, mostly belonging to the indigenous group of the Purépechas, to have a municipal authority different from the legally established figure, who would be appointed by vote and whose duties and rights would be established through autonomous means following their usos y costumbres (customary law) (Aragón Andrade, 2013). The crucial difference of this process with other struggles for autonomous government lies in the fact that it is based on a judicial decision and not on a de facto imposition and its assertion against state law (Ibid, p. 3).

Revising the account of the leading lawyer of the case, Aragón Andrade, a variety of points called my attention. The way he presents the sequence of events and (legal) responses makes it possible to discover how the perspective taken transcends the frame of the 'modern' lawyer. As a conflict and peace worker, he acknowledges his own role within a broader web of interaction and also uses many abilities beyond his knowledge of legal tools in a mechanistic sense, focusing particularly on the importance of a systemic understanding, contextual and holistic awareness, as well as resonance and empathy. Importantly, not only does this particular lawyer have an academic background in history and anthropology, but his whole team is connected to an autonomous space of critical analysis at the regional university, integrating law into the study of humanities.

In his account of the events in Cherán, Aragón Andrade identifies the point of entry to the conflict as connected with a narrative of security which was later judicialized (Ibid, p. 4). However, the main objective of the use of law in this case was situated beyond judicial victory. Rather, the lawyers and plaintiffs understood this legal procedure as a particular element embedded in a complex context. They used it for re-shaping the relations of the community with the wider society, where the movement had been presented as illegal and anti-legal. At the same time, the legal procedure made space for the movement to have "one foot in the institutional field and another in social mobilization" (Ibid, p. 18). The main concern, however, was the will of the people of Cherán to avoid becoming divided between political parties, which they saw as the crucial source of their conflict (Ibid, p. 6) - a concern which the lawyers took as a key guideline for their activities.

Consequently, the lawyers worked with an expanded awareness of the conflict. They were aware of the sociocultural and historical background of the conflict, particularly the systematic criminalization of indigenous people, as well as of international and vernacular levels of law. But the most important aspect was that the lawyers were very aware and cautious regarding their own position in the conflict system. Consequently, they put emphasis on "learning from the people of the community and movement of Cherán”, fostering a multicultural and multiepistemic dialogue. The language of modern law was opened in order to be understood and integrated with voices of the people of Cherán with the aim of giving "clarity and effectivity to the communications sent to the authorities" (Ibid, p. 37).

At its base, the approach of the lawyers here is postmodern (along with the assertion of moral notions of justice), and renders void the promises of moral-modern law as well as the modern tag of 'indigenous laws'. Utilizing it strategically for their own discursive interests (Ibid, p. 30) within modern-moral legal arguments. The lawyers themselves aimed to eliminate from their relation with the Cherán people any "traces of 'legal fetishism', of 'trust in law and the tribunals, etc.", proposing an instrumental use of law (Ibid). This shift to a postmodern approach took shape in their integration of and interaction with a harmonic understanding of law, which was aimed at communal balance and conciliation (Ibid, p. 12).

First of all, this type of engagement influenced the relation of the Cherán people with state law and with the lawyers (Ibid, p. 24). While the unexpected positive legal result had crucial importance in this regard, the very engagement with the community undoubtedly contributed to this transformation. The team of lawyers insisted, for example, on the direct encounter of the comuneros with the judges, allowing them to defend their situation in their own language, "the stories which due to the legal form remained invisibilized in the judicial documents" (Ibid, p. 36). The lawyer became a discreet facilitator of this encounter (Ibid, pp. $35 \mathrm{f}$.) that aimed to sensitize the judges in order for them to orient their decision with a more thorough understanding of the situation. Furthermore, the lawyers emphasized particularly the value of arguments "not necessarily legal and with voices with more authority in social terms" 
(Ibid, p. 36). In other words, they searched for a resonance beyond legal rationality.

In the eyes of the legal team, the comuneros owned the whole process, and the lawyers provided support in their interaction with the language of the state institutions. Importantly, the lawyers conceived of themselves as participants of a common effort in solidarity, which was marked by the quality of interpersonal relations and which also required the crucial activities of a variety of collectives, alternative communication media, musicians and intellectuals (Ibid, p. 32). Thus, here, the law participated in making a platform of dialogue and assertion of plural needs not only by regarding the particular conflict but also by going beyond it.

\section{FINAL REMARKS}

In the previous pages I have dealt with a variety of aspects in which the law meets the realm of transrationality and elicitive conflict transformation. While law is usually explained in terms of moral and modern approaches to peace, often its energetic aspects are forgotten and repressed. In the last few decades, the recognition that 'law' exists beyond the limits of formal state law not only opens the door for the acknowledgement of many legal cultures in terms of indigenous and non-indigenous, but also allows for the recognition that law is founded on the most intimate and sacred aspects of each human being. Most importantly, non-mechanistic understandings of law are not restricted to the imagined Others of Eurocentric traditions. In fact, there are symbolic and mythic worlds where archetypes of life and rebirth are intimately connected with law and justice. The relation to cosmic energy, though repressed from the modern legal imaginary, is always present within modern law and gives meaning to our actions in human communities.

Moreover, it becomes apparent that these energetic understandings of law oriented rather to a vision of cosmic harmony, uniting the person, the community and the whole of creation, are in constant interaction with the traditional framework of state law that includes a modern and moral understanding of law, as well as with postmodern perspectives on law, which support their multiple claims for legitimacy. In other words, all four quadrants of Wilber and Dietrich interact creating different fields of tension and relaxation. The relations of these different aspects can be appreciated through an integrative or transrational understanding of law. The awareness of the relationality amongst these different fields allows to lead the actions to be taken within a conflict in order to contribute to its holistic transformation.

Integrating this profound aspect explicitly, both in aesthetic and ethical terms, into our understanding of law and justice, is crucial in order to support holistic processes of conflict transformation. It is particularly important to take this into account when it comes to shaping current judicial reforms and broader socio-legal developments. Taking a holistic and complex perspective on human-beings-inrelation within social conflict, and thus incorporating a transrational perspective on law and peace explicitly, enables us and future generations to address the challenges of current conflicts, enacting their potential and enriching our lively coexistence.

After all, today, it is up to us to shape the dances of Law and Life.

\section{References}

ARAGÓN ANDRADE, Orlando (unpublished). El derecho en insurrección. El uso contra-hegemónico del derecho en el movimiento purépecha de Cherán [2013].

BENÍTEZ-SCHAEFER, Florencia (unpublished). Plurality in legal development. A critical appraisal of modern and postmodern models of legal development. Doctoral Thesis. University of Vienna [2012].

DAVIDHEISER, Mark (2006). “Joking for peace. Social organization, tradition, and change in Gambian conflict management". Cahiers d'Études Africaines. Vol. 4, no. 184, p. $835-859$.
DIETRICH, Wolfgang (2008).Variationen über die vielen Frieden. Vol. 1: "Deutungen”. Wiesbaden: VS Verlag. http://dx.doi.org/10.1007/978-3-531-91800-6

DIETRICH, Wolfgang (2013). Elicitive conflict transformation and the transrational turn in peace politics. W. Sützl; V. Hindley (trans.). London: Palgrave Macmillan. http://dx.doi.org/10.1057/9781137035066

DIETRICH, Wolfgang (unpublished). Elicitive conflict mapping. Wien/Münster: LIT Verlag.

KUPPE, Rene (2010). Indigene Rechtsprechung und staatliches Recht in Lateinamerika. Eschborn: GTZ. 
LEDERACH, John Paul (2003). The little book of conflict transformation. Intercourse, PA: Good Books.

OHCHRNU (2011) Report 2011 [online]. [Accessed 10 October 2014]. http://www2.ohchr.org/english/ ohchrreport2011/web_version/ohchr_report2011_ web/index.html

RÍO NEGRO (2002). "Absolvieron a un hombre invocando la 'diversidad cultural”, November 26, 2002.
SIERRA, Juan Carlos; JIMÉNEZ, Eva María; BUELACASAL, Gualberto (coords.) (2010). Psicología forense: manual de técnicas y aplicaciones. Madrid: Biblioteca Nueva Universidad.

VALLEJO PIEDRAHÍTA, Catalina (2012). Plurality of peaces in legal action. Analyzing constitutional objections to military service in Colombia. Zürich/Münster: LIT Verlag.

WILBER, Ken (2000). Sex, ecology, spirituality: the spirit of evolution. Boston: Shambala.

\section{Recommended citation}

BENÍTEZ-SCHAEFER, Florencia (2014). "Law as Transformative Conflict Work - A Transrational Approach" [online article]. Journal of Conflictology. Vol. 5, Iss. 2, pp. 81-89. Campus for Peace, UOC. [Consulted: dd/mm/ yy].

http://www.uoc.edu/ojs/index.php/journal-of-conflictology/article/view/vol5iss2-benitez-schaefer/vol5iss2-benitez-schaefer-en

DOI: http://dx.doi.org/10.7238/joc.v5i2.2007

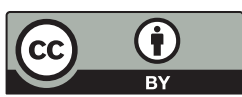

The texts published in this journal are - unless indicated otherwise - covered by the Creative Commons Spain Attribution 3.0 licence. You may copy, distribute, transmit and adapt the work, provided you attribute it (authorship, journal name, publisher) in the manner specified by the author(s) or licensor(s). The full text of the licence can be consulted here: http://creativecommons.org/licenses/by/3.0/es/deed.en.

\section{About the author}

\section{Florencia Benítez-Schaefer}

Florencia.Benitez-Schaefer@uibk.ac.at

Faculty Member of the UNESCO Chair for Peaces Studies, University of Innsbruck, Doctor of Law, University of Vienna, Coordinator of the Collective Arte y Paz, Board Member of AARESPECT, Facilitator of diverse courses on Conflict Transformation.

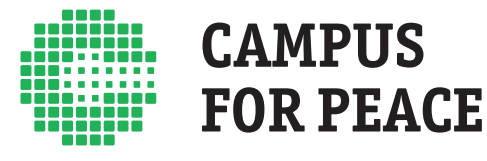

